\title{
BROWN SPOT CAUSED BY CURVULARIA SPP., A NEW DISEASE OF ASPARAGUS
}

\author{
B. SALLEH ${ }^{1}$, A. SAFINAT ${ }^{1}$, L. JULIA ${ }^{2}$ and C.H. TEO ${ }^{3}$ \\ ${ }^{1}$ School of Biological Sciences, Universiti Sains Malaysia, 11800 Penang, Malaysia \\ ${ }^{2}$ Laboratory of Plant Pathology, Agricultural Research Centre, P.O. Box 3, 89207 Tuaran, Sabah, Malaysia \\ ${ }^{3}$ Laboratory of Plant Pathology, Agricultural Research Centre, Semogok, P.O. Box 977, 93720 Kuching, \\ Sarawak, Malaysia
}

\begin{abstract}
The distribution, aetiology and symptomatology of a new disease on asparagus ferns, which we have termed brown spot, is described. Descriptions of and a key to identification of the causal organisms, Curvularia brachyspora, C. eragrostidis, $C$. lunata and $C$. pallescens, are also presented. Pathogenicity tests showed that $C$. lunata was the dominant and most virulent of the four species. Inoculation with conidial suspensions or mycelial transfers through wounded ferns were more effective in inducing the disease than inoculations on unwounded ferns. This is the first record of $C$. brachyspora in Malaysia and the first report of this disease on asparagus.
\end{abstract}

Key words: Malaysia/Plant diseases/Brown spotJCurvularia brachyspora/Curvularia eragrostidts/Curvularia lunata/Curvularia pallescens/Asparagus.

\section{INTRODUCTION}

Asparagus (Asparagus officinalis L.) was introducted into Malaysia from Taiwan in the 1950s. Although it is a fairly new crop, asparagus has become a preferred vegetable especially by Malaysians in the higher income groups. Its caloric and nutrient contents are comparable to those of the four most popular local vegetables i.e. kailan (Brassica alboglabra Bailey), Chinese cabbage (B. chinensis L.), cauliflower (B. oler-cea L. var. botrytis) and sawi (B.juncea Bailey) (Anon. 1985).

During a series of investigations on causes of degeneration in asparagus farms established for experimental or commercial purposes throughout Malaysia in 1989-90 (Salleh 1990), a new disease was observed on all varieties. In this paper we report the distribution, aetiology and symptomatology of the disease. 


\section{MATERIALS AND METHODS}

\section{Disease survey and aetiology}

Eighteen asparagus farms established for experimental or commercial purposes throughout Malaysia were visited and sampled at least twice in 1989-90 (Fig. 1). The last three of the farms are situated in the East Malaysia (Malaysian territory of the Borneo Island).

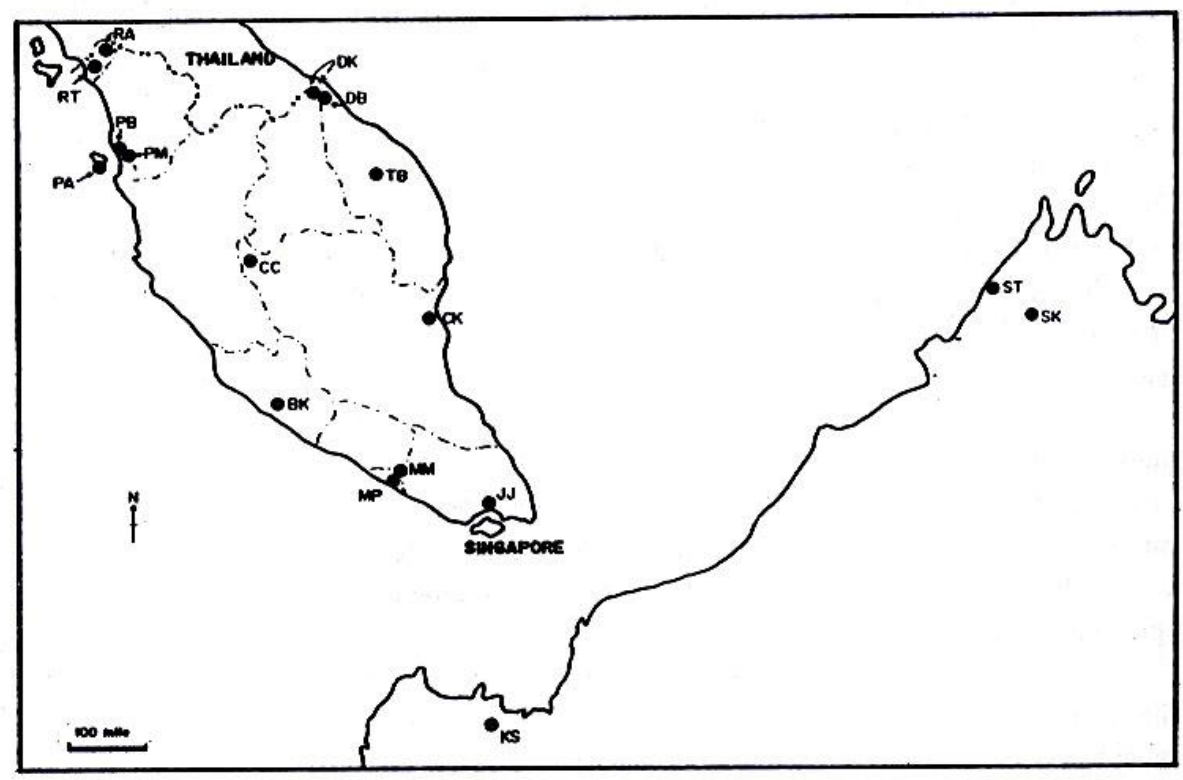

Figure 1. Asparagus disease sampling sites throughout Malaysia (1989-1990)

Plant parts showing brownish lesions were collected and the causal organisms were isolated as previously described (Salleh \& Sulaiman 1984). Single conidia of the dominant isolates (Curvularia spp.) which developed from the diseased materials were placed on potato-sucrose-agar (PSA) plates and incubated under standard incubation conditions described earlier (Salleh \& Sulaiman 1984). Growth of the colonies was 
measured after four days of incubation. Curvularia species were identified using the diagnostic characters proposed by Ellis $(1971$; 1976) and Sivanesan (1987), and later confirmed by the Commonwealth Mycological Institute, UK. Conidial suspensions from monoconidial stock cultures were preserved in $15 \%$ glycerol in liquid nitrogen (Salleh \& Strange 1988), and fresh monoconidial cultures on potato-dextrose-agar (PDA) slants were covered with sterile mineral oils and kept at $4^{\circ} \mathrm{C}$.

\section{Pathogenicity test}

Pathogenicity tests of selected isolates of all four species of Curvularia isolated from asparagus were carried out on healthy 9 month-old asparagus seedlings, varieties Mary Washington (MW) and UC 157. The seeds were tested for fungal contamination by plating on PSA plates. Apparently healthy and non-cracked seeds were sown in sterile soil in polyethylene bags (diameter $20 \mathrm{~cm}$ ) in a greenhouse with natural lighting for nine months. The seedlings were kept healthy by spraying a mixture of a fungicide (benomyl or propineb) and an insecticide (diazinon or aldrin) monthly until the seventh month. The plants were fertilized bimonthly with a granular NPK (15:15:15) fertilizer.

The first method of inoculation was conducted as follows : Conidial suspensions of Curvularia spp. were prepared by flooding 7 day-old PSA plates with $10 \mathrm{ml}$ sterile water containing $0.05 \%$ Tween 80 . After gentle agitations, the liquid was decanted and the concentration adjusted to 1 x 10 conidia/ml. Inocula were sprayed in the evening onto aseptically wounded or unwounded ferns at the base, middle, branch and tip of plants at growth stage 5 or 6 (fully developed ferns) (Bansal et al. 1986). Wounds were made by pricking the plants with sterile needles. Parts of the ferns were surface sterilized with $70 \%$ alcohol prior to wounding. Control wounded or unwounded ferns were sprayed with sterile water.

A second method of inoculation was carried out by placing mycelial plugs from the plates onto similar inoculation points of the aseptically wounded ferns. The inoculation points were wrapped with sterile moistened cotton wool and tied with an adhesive plastic for $48 \mathrm{~h}$. Similar points on unwounded stems and branches wrapped in the same manner served as controls.

For both conidial spray and mycelial plug inoculations, mixed inocula which comprised of all four species of Curvularia were also used on different set of plants throughout the experiments.

Plants in each polyethylene bag were covered with transparent plastic bags overnight. The plastic chambers were kept moist by spraying $10 \mathrm{ml}$ sterile water into each chamber after inoculation. All treatments were replicated ten times (10 plants; one in each polyethylene bag). Symptom development was observed every other day. The 
length of the lesion was measured four weeks after inoculation. Reisolations were made from all infected and control ferns and the resulting fungi subcultured on PSA and reidentified.

\section{RESULTS AND DISCUSSION}

\section{Disease survey and aetiology}

A new disease with typical greyish brown spots was observed on the ferns of all varieties of asparagus planted in all 18 sampling sites throughout Malaysia (Table 1). The disease was apparently more severe on asparagus planted at lower altitudes (16 sites) where mean daily temperatures were significantly higher than those of the same variety at higher altitudes ( 2 sites: Cameron Highlands and Kundasang). Young ( $<2$ years) asparagus fields were generally found with only a few infected ferns while in older fields, particularly those at the lower altitudes, $10-25 \%$ of the older ferns had been attacked. It was not clear whether the increase in disease at higher temperature resulted from increased pathogen virulence or increased plant susceptibility. As is common for many necrotic diseases, both relative humidity and temperature probably play important roles in disease development.

Sixty percent of the fungal isolates recovered from asparagus ferns with small oval brown spots were Curvularia spp., while Alternaria spp. and Fusarium spp. comprised the remaining $40 \%$. The role of Alternaria spp. and Fusarium spp. in the asparagus brown spot complex is presently being studied and will be described elsewhere. Based on cultural characteristics and conidial structures, the Curvularia isolates were identified as Curvularia lunata (Wakker) Boedijn, Curvularia pallescens Boedijn, Curvularia eragrostidis (Henn.) Mayer and Curvularia brachyspora Boedijn. Perfect stages of the fungi were not observed either in culture or on infected asparagus plants in nature. Amongst the species of Curvularia isolated from asparagus in Malaysia, $C$. lunata was the most frequent $(85 \%)$, followed by $C$. pallescens $(32.0 \%)$, C. eragrostidis (18.2\%) and C. brachyspora $(11.5 \%)$. The description and a key for identification of the Curvularia species isolated from asparagus in Malaysia are as follows :

\section{Curvularia brachyspora Boedijn (Fig. 2)}

Colonies blackish grey, black, cottony or hairy; growth rate $5.5-6.1 \mathrm{~cm}$ after four days. Conidia 16.5 - 26.4 x 9.9 - 16.5 um, dark or light brown, solitary, simple, some slightly curved, clavate, ellipsoidal, broadly fusiform, 3-septate, dark bands at the septa, mostly truly median and asymmetrical. The third cell from the base is conspicuously 
larger, broader and darker than the others. Conidiophores macronematous, monone-matous, straight, flexous, often geniculate, sometimes nodose, brownish and smooth.

Although the type species of Curvularia brachyspora was originated from Java, the presence of this species has never been reported in Malaysia. Elsewhere, it was isolated from Agave, Digitaria, Dracaena, Olea, Oryza, Saccharum, Triticum and air (Ellis 1971; Sivanesan 1987).

Table 1. Distribution of asparagus brown spot caused by Curvularia spp. at 18 sampling sites in Malaysia 1989-90)

\begin{tabular}{|c|c|c|c|c|c|c|c|}
\hline \multirow{3}{*}{$\begin{array}{l}\text { Sampling } \\
\text { sites }\end{array}$} & \multirow{2}{*}{\multicolumn{2}{|c|}{$\begin{array}{c}\text { Temperature }^{2} \\
{ }^{\circ} \mathrm{C}\end{array}$}} & \multirow{3}{*}{$\begin{array}{c}\text { Rainfall }^{3} \\
\text { (mm) }\end{array}$} & \multicolumn{4}{|c|}{ Curvularia species } \\
\hline & & & & \multirow[t]{2}{*}{ Lunata } & \multirow[t]{2}{*}{ pallescens } & \multirow[t]{2}{*}{ eragrostidis } & \multirow[t]{2}{*}{ brachyspora } \\
\hline & Day & Night & & & & & \\
\hline${ }^{1}$ Bukit Temiang (RT) & 32.1 & 21.6 & 272.4 & $+^{4}$ & + & + & + \\
\hline Kampung Cikgu Ali (RA) & 32.5 & 21.0 & 267.3 & + & + & + & + \\
\hline${ }^{1}$ Bertam (PB) & 31.0 & 22.9 & 321.0 & + & + & + & + \\
\hline${ }^{1}$ Kubang Menerong (PM) & 31.3 & 22.9 & 304.2 & + & + & + & + \\
\hline${ }^{1}$ Relau (PA) & 31.0 & 23.4 & 241.6 & + & + & + & + \\
\hline${ }^{1}$ Sungai Ara (PA) & 31.0 & 23.4 & 241.6 & + & + & + & + \\
\hline Kuala Berang (TB) & 30.6 & 22.9 & 205.1 & + & + & + & - \\
\hline${ }^{1}$ Kota Bharu (DK) & 31.6 & 23.2 & 313.9 & + & + & - & - \\
\hline Bacok (DB) & 32.3 & 22.1 & 403.4 & + & - & - & - \\
\hline${ }^{1}$ Cameron Highlands (CC) & 24.1 & 14.1 & 230.2 & + & + & - & - \\
\hline Kuantan (CK) & 29.8 & 22.5 & 261.8 & + & - & - & - \\
\hline${ }^{1} \mathrm{Klang}$ (BK) & 32.6 & 22.8 & 240.9 & + & + & + & - \\
\hline Lorong Pandan (MP) & 31.7 & 22.8 , & 289.5 & + & + & + & - \\
\hline Merlimau (MM) & 31.3 & 22.0 & 214.6 & + & + & + & - \\
\hline Johor Bharu (JJ) & 31.5 & 22.4 & 203.6 & + & + & - & - \\
\hline Semongok (KS) & 33.6 & 21.5 & 349.3 & + & + & - & - \\
\hline${ }^{1}$ Tuaran (ST) & 31.9 & 22.9 & 197.7 & + & + & - & - \\
\hline Kundasang (SK) & 23.9 & 16.3 & 245.0 & + & - & - & - \\
\hline
\end{tabular}

${ }^{1}$ For experimental purposes

${ }^{2}$ Daily average of maximum (day) and minimum (night) temperatures

${ }^{3}$ Monthly average

${ }^{4}+$ Present, - Absent

\section{Curvularia eragrostidis (Henn.) Meyer (Fig. 3)}

Colonies blackish grey, black, hairy or cottony; growth rate 5.7 - $6.4 \mathrm{~cm}$ after four days. Conidia 16.5 - 24.75 x 9.9 - 16.5 um, dark brown, solitary, simple, broadly ellipsoidal, 3 -septate, symmetrical, dark bands at the septa are quite thick and truly 
Brown spot caused by Curvularia spp., - B. Salleh et al.

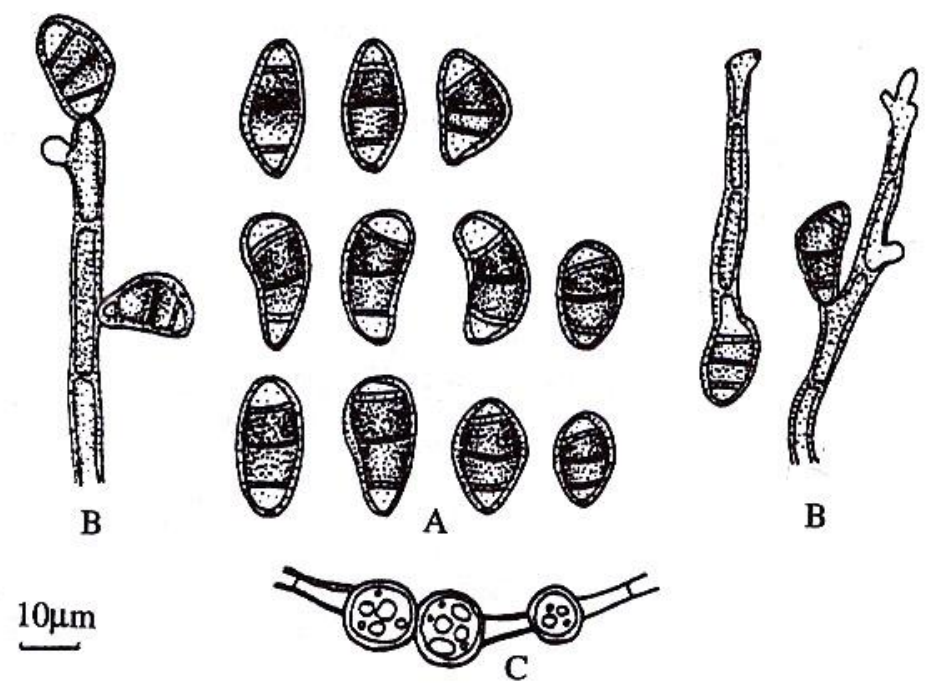

Figure 2. Curvulariabrachyspora Boedijn

A: Conidia; B: Conidiophores; C: CMamydospores

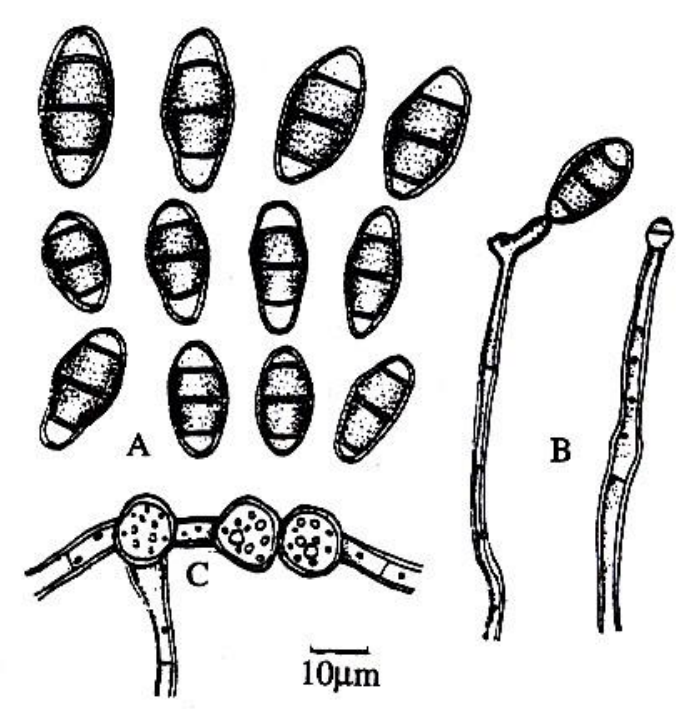

Figure 3. Curvularia eragrostidis (Henn.) Meyer A: Conidia; B: Conidiophores; C: Chlamydosporcs 
median. Usually the second and third cells are the same size, and broader than the others. Conidiophores macronematous, mononematous, mostly straight, often branched, geniculate, often nodose, brown and usually smooth.

C. eragrostidis has been isolated from a wide variety of plant hosts and other substrates worldwide, including Malaysia. It causes minor leaf spots on several grami-nicolous hosts (Hawksworth 1990).

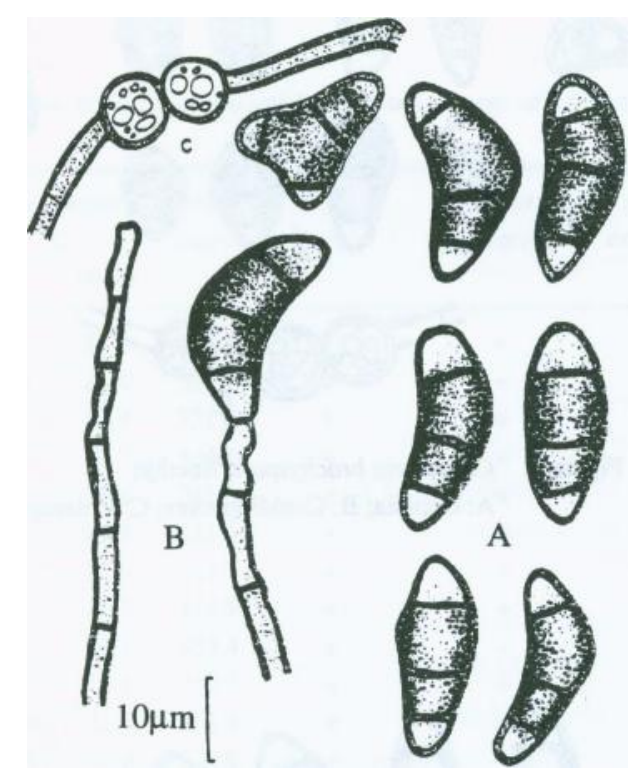

Figure 4. Curvularia lunata (Wakker) Boedijn

A: Conidia; B: Conidiophores; C: Chlamydospores

\section{Curvularia lunata (Wakker) Boedijn (Fig. 4)}

Colonies are dark grey or black, effuse, cottony or velvety; mycelium immersed; growth rate 6.0 - $7.6 \mathrm{~cm}$ after four days. Stroma dark brown. Conidia 14 - 28 x 7 - $13 \mu \mathrm{m}$, dark brown, solitary, often curved on the middle septum (not median); predominantly 3-septate and rounded at the apex. Very few $(<3 \%)$ triradiate stauroconidia. Conidiophores dark gray or brownish black, macronematous and mononematous, po-lytretic, straight or flexous and smooth.

C. lunata is often associated with grain moulds of sorghum and millet, and also causes a leaf spot on sorghum (Singh 1982). C. lunata is common and widespread in the tropics, including Malaysia, and may be recovered from many different substrates (Ellis 1971). 


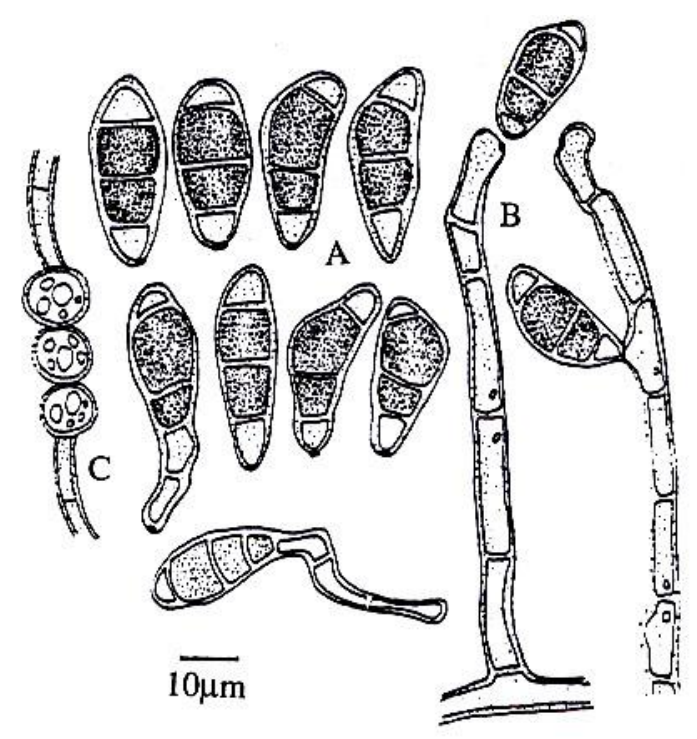

Figure 5. Curvularia pallescens Boedijn

A: Conidia; B: Conidiophores; C: Chlamydospores

\section{Curvularia pallescens Boedijn (Fig. 5)}

Colonies usually grey or pale grey, effuse, cottony or velvety; mycelium immersed; growth rate $7.0-7.7 \mathrm{~cm}$ after four days. Stroma gray or pale gray. Conidia $7-9 \times 3-4 \mu \mathrm{m}$, pale or very pale brown, solitary, usually straight or only slightly curved; predominantly 3 -septate. Conidiophores gray or pale gray, macronematous or monone-matous, polytretic, straight or flexous, smooth and brown.

C. pallescens is common on many different substrata especially in the tropics (Ellis 1971; Sivanesan 1987).

Key for the identification of Curvularia spp. isolated from asparagus ferns showing brown spot in Malaysia

Conidia remaining smooth-walled and predominantly

3-septate 1

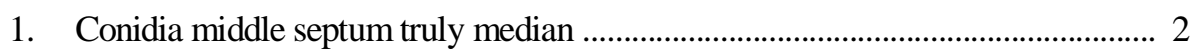

Conidia middle septum not median ............................................................... 3 
2 Conidia symmetrical, dark bands at the septa are quite thick, usually the third and the second cells are of the same size eragrostidis

Conidia asymmetrical and mostly truly median brachyspora

3. Conidia straight or slightly curved, $7-9 \mathrm{x}$

3-4 u,m pallescens

Conidia straight or curved, sometimes have triradiate stauroconidia, $14-28 \times 7-13$ (im lunata

\section{Pathogenicity test}

Pathogenicity tests showed that all isolates of the four Curvularia species obtained from asparagus showing brown spot symptoms in Malaysia were pathogenic to both varieties of asparagus i.e. MW and UC 157 tested. Once the symptoms occurred, there was no difference in the visible symptoms caused by the four species of Curvularia. The first symptom of asparagus brown spot appeared as a water-soaked lesion which later developed into a brown spot with a brownish red margin and brownish grey center. The slighty sunken spot, particularly that caused by $C$. lunata, gradually became dark brown and developed from 0.7 to $5.0 \mathrm{~cm}$ within 28 days. The spot developed upwards and sideways along the circumference and coalesced, hence girdling the stem. At this stage, the entire stem appeared brown with irregular dark-brown patches (Fig. 6), quite similar to the symptoms observed on rice stem infected by blast (Pyricularia oryzae). Under favourable conditions, heavily infected ferns were easily broken and eventually killed. No symptoms were observed on the spears and crowns.

Inoculations of wounded or unwounded plants with either conidial suspensions or mycelial plugs on fully developed asparagus ferns resulted in symptoms identical to those seen in the field. $C$. eragrostidis, $C$. pallescens and $C$. brachyspora only caused milder symptoms on ferns inoculated through wounds and the first symptoms appeared later ( $\pm 2-3$ weeks) than those induced by $C$. lunata. Isolates of these three species did not produce visible symptoms on unwounded plants even up to 4 weeks after inoculation. Reisolation from artificially infected ferns showing brown spot symptoms yielded only the pathogens that were used for inoculation. Reisolation from plants infected with a mixture of all four species always yielded $C$. lunata. Therefore we concluded that $C$. lunata was the most dominant and virulent species of Curvularia in this context. These greenhouse results are similar to the disease incidence and severity seen under field conditions. Wound inoculation using fungal mass was the best $(\mathrm{p}<0.01)$ of the four methods tested since the first typical symptom of brown spot i.e. watersoaked spot, caused by $C$. lunata was observed within seven days of inoculation. The ino- 


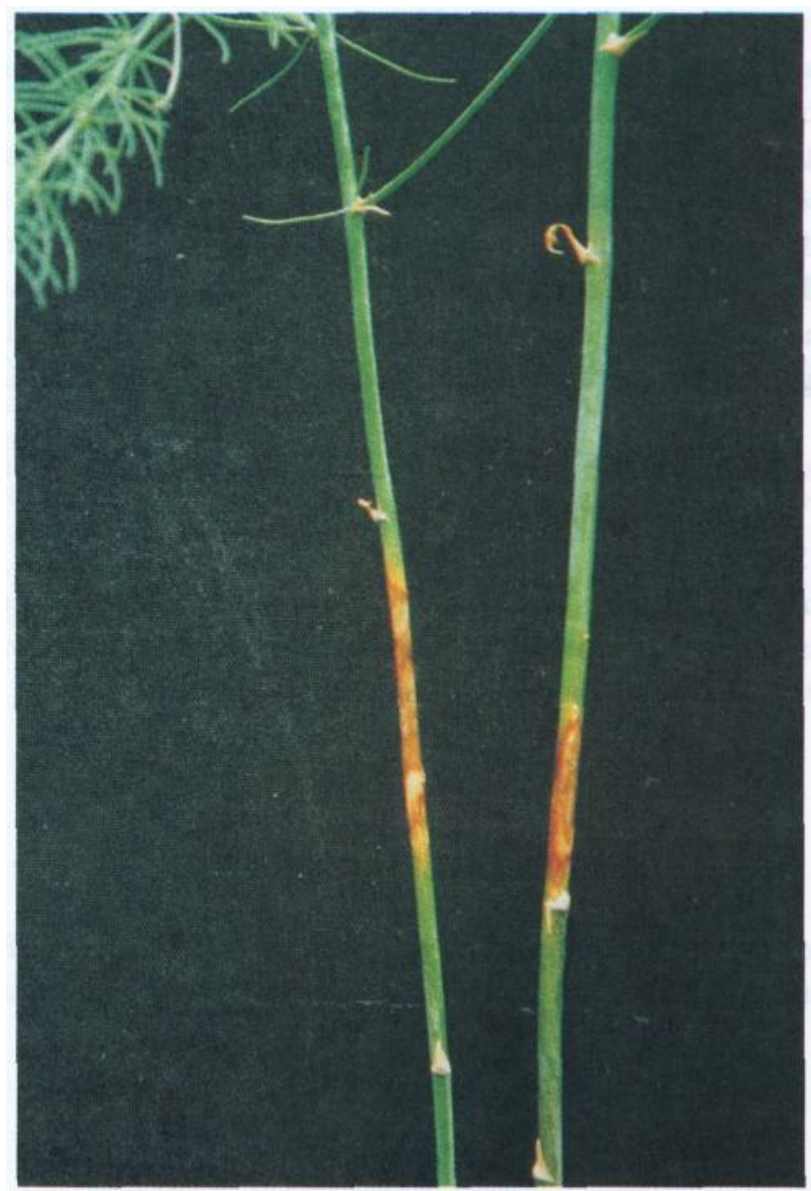

Figure 6. An advanced stage of brown spot on asparagus stem caused by Curvularia lunata. Note the irregular dark-brown patches.

culation was more effective on the upper parts and branches than on the base and middle parts of the ferns. A wound was not an absolute requirement for disease development since the pathogens also may enter through stomata, and/or natural and accidental wounds. In other diseases of asparagus, e.g. dead stem caused by Fusarium culmorum, inoculation succeeded only when the stems were wounded (van Bakel \& Krom-Kerstens 1974). Infection by the purple,spot pathogen, Stemphylium vesicarium on asparagus cv. MW was more numerous arfd occurred at shorter wetting durations on wounded than on 
unwounded plants (Johnson \& Lunden 1986). They also showed that wounds produced by blowing sand could serve as entry points for the infection of the pathogen. In scanning electron micrographs of Fusarium proliferation, the causal agent of reddish-brown rot of asparagus, Nik Norulaini \& Salleh (1990) clearly showed that this pathogen successfully penetrated its host only through wounds and stomata. In all asparagus fields visited during the present survey, we observed numerous bark-eating caterpillars and mollusks that could easily have created wounds that Curvularia spp. and other pathogens could use to enter the host. Therefore, effective pest control probably will lead to significant reduction of brown spot and other diseases of asparagus in the field.

Yield losses occurring as a result of infections by Curvularia spp. on asparagus in Malaysia have not been ascertained, but based on our present survey we would estimate between $15-35 \%$.

Based on these symptoms and aetiology, we proposed that this disease complex on asparagus ferns denoted as brown spot. This report is the first on brown spot of asparagus in Malaysia, and to our knowledge, anywhere in the world.

\section{ACKNOWLEDGEMENTS}

This research was supported by the Government of Malaysia (IRPA 123/31037 2401). We thank the owners and persons in charge of the eighteen asparagus sampling sites.

\section{REFERENCES}

ANON. 1985. Tanaman Asparagus Tanah Rendah. Risalah Pertanian Bil. 55. Jabatan Pertanian Semenanjung Malaysia, Kuala Lumpur. 27 p.

BANSAL, R.K., S.A. MENZES and P.O. BROADHURST. 1986. Screening of Asparagus Species for resistance to Stemphylium leaf spot. New Zealand Journal of Agricultural Research 29: 539-545.

ELUS, M.B. 1971. Dematiaceous Hyphomycetes. Commonwealth Mycological Institute, London. 452-459 pp.

ELuS, M.B. 1976. More Dematiaceous Hyphomycetes. Commonwealth Mycological Institute, London. 404-411pp.

HAWKSWORTH,D.L. 1990. CMI description of fungi and bacteria. Mycopathologia 111: 109-130.

JOHNSON.D.A. and J.D. LUNDEN. 1986. Effects of wounding and wetting duration on infection of asparagus by

Stemphylium vesicarium. Plant Disease 70: 419-420. 
NIK NORULAINI, N.A.R. and B. SALLEH. 1990. In vitro inoculation of asparagus tissue culture plantlets with vegetative hyphae of Fusarium proliferatum. In: Proceedings of the $3^{\text {rd }}$ International Conference on Plant Protection in the Tropics, Genting Highlands, Malaysia, pp. 127-129.

SALLEH, B. 1990. Crown rot caused by Fusarium proliferatum, a new disease of asparagus in Malaysia. In: Proceedings of the $3^{\text {rd }}$ International Conference on Plant Protection in the Tropics, Genting Highlands, Malaysia, p. 343 (Abstract). SALLEH. B. and B. SULAIMAN 1984. Fusaria associated with naturally diseased plants in Penang. Journal of Plant Protection in the Tropics 1: 47-53.

SALLEH, B. and R.N. STRANGE. 1988. Toxigenicity of some fusaria associated with plant and human diseases in the Malaysian Peninsula. Journal of General Microbiology 134: 841-847.

SINGH, R.S. 1982. Plant Pathogens-the Fungi. Oxford and IBH Publishing, London. 342pp.

SIVANESAN, A. 1987. Graminicolous species of Bipolaris, Curvularia, Drechslera, Exserohilum and their teleomorphs. Mycological Papers 158.pp. 261.

VAN BAKEL, J.M.M. and J.J. KROM-KERSTENS. 1974. Dead stem disease of asparagus caused by Fusarium culmorum. Netherlands Journal of Plant Pathology 80:104-109. 